\title{
Review
}

\section{Continuous Drug Delivery Aiming Continuous Dopaminergic Stimulation in Parkinson's Disease}

\author{
Daniel J. van Wamelen ${ }^{\mathrm{a}, \mathrm{b}, \mathrm{c}, 1, *}$, Sotirios Grigoriou ${ }^{\mathrm{d}, 1}$, K. Ray Chaudhuri ${ }^{\mathrm{a}, \mathrm{b}}$ and Per Odin $^{\mathrm{d}, \mathrm{e}}$ \\ a Institute of Psychiatry, Psychology \& Neuroscience at King's College London, Department of Basic \& \\ Clinical Neuroscience, De Crespigny Park, London, United Kingdom \\ ${ }^{\mathrm{b}}$ Parkinson Foundation International Centre of Excellence, King's College Hospital, Denmark Hill, \\ London, United Kingdom \\ ${ }^{\mathrm{c}}$ Donders Institute for Brain, Cognition and Behavior, Radboud University Medical Centre, Nijmegen, \\ The Netherlands \\ ${ }^{\mathrm{d}}$ University of Lund, Faculty of Medicine, Lund, Sweden \\ ${ }^{\mathrm{e}}$ University Hospital Reinkenheide, Bremerhaven, Germany
}

Accepted 8 November 2018

\begin{abstract}
Continuous dopaminergic stimulation in Parkinson's disease (PD) has several advantages over pulsatile, noncontinuous, stimulation. These therapies currently consist of pump-based and transcutaneous therapies and are based on a more constant delivery of the dopaminergic drug resulting in continuous dopaminergic stimulation and a more stable treatment effect. Several clinical and experimental observations have shown that continuous stimulation of dopaminergic receptors induces fewer complications, such as dyskinesia, compared to pulsatile stimulation. Currently available nonoral pharmacological continuous therapies in PD include the transdermal Rotigotine (RTG) patch, infusion therapies with Apomorphine and Intrajejunal Levodopa (IJLI) and the Rivastigmine patch. Here we aim to provide a concise review of these current therapies and discuss ongoing and future developments of continuous non-oral pharmacological dopaminergic therapies in PD.
\end{abstract}

Keywords: Parkinson's disease, apomorphine, infusion pumps, rivastigmine, rotigotine

\section{INTRODUCTION}

Continuous dopaminergic stimulation in Parkinson's disease (PD) has several advantages over pulsatile, non-continuous, stimulation. Several clinical

\footnotetext{
${ }^{1}$ These authors contributed equally to this work.

*Correspondence to: Daniel J. van Wamelen, MD, PhD, Institute of Psychiatry, Psychology \& Neuroscience at King's College London, Department of Basic \& Clinical Neuroscience, De Crespigny Park, London, SE5 8AF, United Kingdom. Tel.: +44 2032997189; E-mail: Daniel.van_wamelen@kcl.ac.uk.
}

and experimental observations have shown that continuous stimulation of dopaminergic receptors induces fewer complications, such as dyskinesia, compared to pulsatile stimulation $[1,2]$. Moreover, evidence suggests that early treatment with long acting dopaminergic stimulation, such as dopamine agonists, has a reduced rick of motor complications compared to immediate release preparations, such as Levodopa, although Levodopa (LD) is more effective in improving motor symptoms and some nonmotor symptoms in experimental models of animals 
[3-5]. Moreover, continuous therapy has the capability of simplifying treatment regimes and could improve compliance [6]. Significant medication noncompliance has been reported to be as high as $67 \%$ among PD patients [7] and only a quarter of patients adhere to medication times [8]. Simplification of regimes improves patient adherence [9].

As gastrointestinal dysfunction in PD has now been recognized to be part of the nonmotor endophenotype of PD and occur in all stages of the disease, leading to absorption problems of oral medication, the focus of continuous drug delivery in PD should be focused towards non-oral therapies $[10,11]$. Currently available non-oral therapies in PD consist of the transdermal Rotigotine (RTG) patch, infusion therapies with Apomorphine and Intrajejunal Levodopa (IJLI) and Rivastigmine patch. Here we aim to provide a concise review of these current therapies and discuss ongoing and future developments of continuous non-oral pharmacological dopaminergic therapies in PD.

\section{CONTINUOUS DRUG DELIVERY (CDD) IN PD}

Many attempts have been or are being currently made in order to provide oral levodopa preparations with longer distribution times, more stable pharmacokinetics to mimic CDD and reduce the number of tablets needed daily. A notable example includes DM-1992/ Depomed, a gastroretentive form of Levodopa/Carbidopa for the treatment of advanced PD [12]. On the other hand, non-oral, continuous, dopaminergic treatments are becoming the treatment of choice for PD patients with ON-OFF fluctuations and levodopa-associated dyskinesias. Other benefits of continuous, non-oral, therapies are their applicability for night-time complaints. These can be both motor symptoms, such as difficulties turning in bed, and non-motor, such as insomnia. The focus of this review will be on non-oral therapies. An overview of available continuous drug therapies, including those under development, is provided in (Fig. 1).

\section{CURRENTLY AVAILABLE \\ LEVODOPA-BASED STRATEGIES}

\section{Continuous Intrajejunal Levodopa Infusion (IJLI) therapy}

IJLI, was first introduced in Sweden in the 1990s [13] and since its introduction much progress has been made in our understanding of the effects of this therapy. IJLI is used for PD patients with advanced disease and a double-blind, placebo-controlled study [14] has demonstrated that continuous intraintestinal levodopa-carbidopa intestinal gel infusion provided a reduction in off-time, increase in on-time without troublesome dyskinesia, and improvement in measures of quality of life when compared with intermittent, oral administration of the drug. Although initially introduced to address motor symptoms in patients who experience wearing-Off, On-periods with troublesome dyskinesia and other motor fluctuations $[15,16]$, it has now been shown IJLI also has a pronounced effect on non-motor symptoms (NMS). IJLI has a clear effect on motor symptoms, with a reduction of up to 3.9 hours/day reduction in Off-time and On-time with dyskinesia [17]. Regarding NMS, the effect was shown at both the level of NMS as a whole (NMS burden) [17, 18], but was especially pronounced for sleep, mood and gastrointestinal problems [17, 19]. In addition, several studies have shown a clear improvement in experienced quality of life, not only in patients on IJLI [14, 17, 18], but also in caregivers [18]. Moreover, a study sponsored by the Industry suggested that costs for IJLI are currently comparable to standard care with oral therapies with per patient costs over the lifetime of the patient estimated at $€ 537,687$ for IJLI compared to $€ 514,037$ for standard care [20]. However, national commissioning bodies in many countries may have different cost benefit values for the use of IJLI. IJLI therapy can be considered for patients with advanced PD and severe motor fluctuations. IILI is less suitable for patients with a poor response to levodopa, pronounced dementia, and the inability to handle the infusion pump. Unlike candidates for deep brain stimulation, however, depression and mild cognitive impairment are not a contraindication and there is also no upper age limit [21].

IJLI therapy is associated with an increased risk for the development of or worsening of pre-existing polyneuropathy (PNP). Up to $9 \%$ of patients on IJLI develop subacute PNP, which is a reason to stop the therapy. Up to half of patients may develop chronic PNP which can be ameliorated or stabilised with vitamin B1 and B12 [22]. Similar development of PNP is also observed with oral Levodopa preparations and it remains unclear whether it is more prevalent in patients on IJLI therapy compared to those on oral therapies [23]. Nevertheless, patients on IJLI should be routinely checked for signs of PNP. Other complications of IJLI include decreased weight 

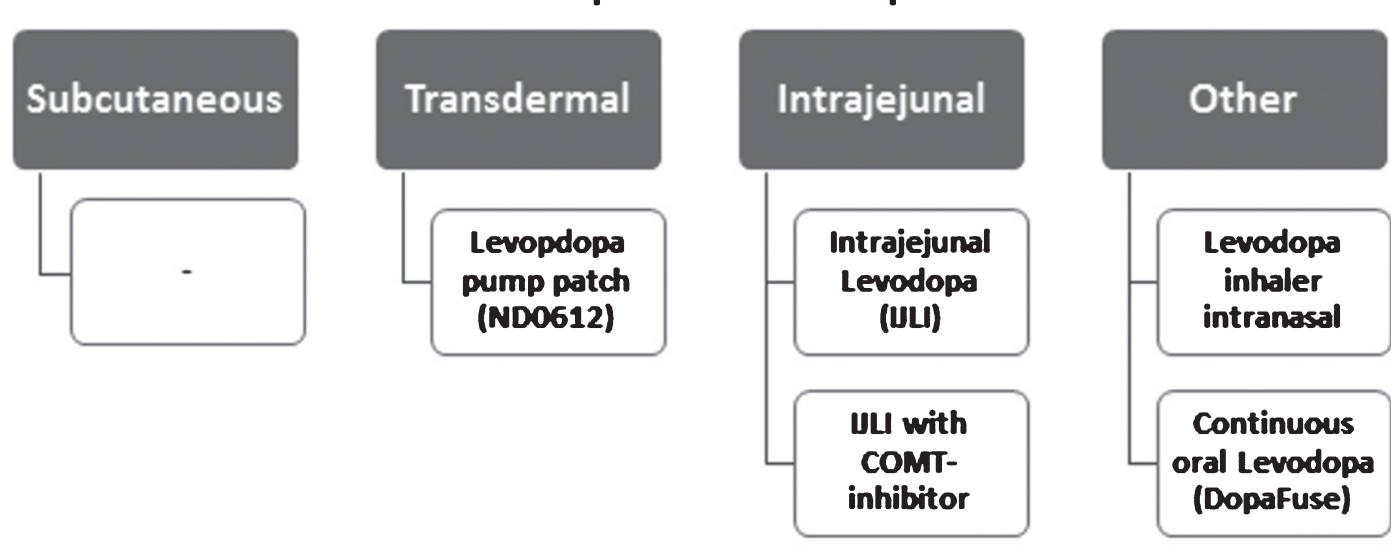

Levodopa-based therapies

\section{Non-Levodopa-based therapies}
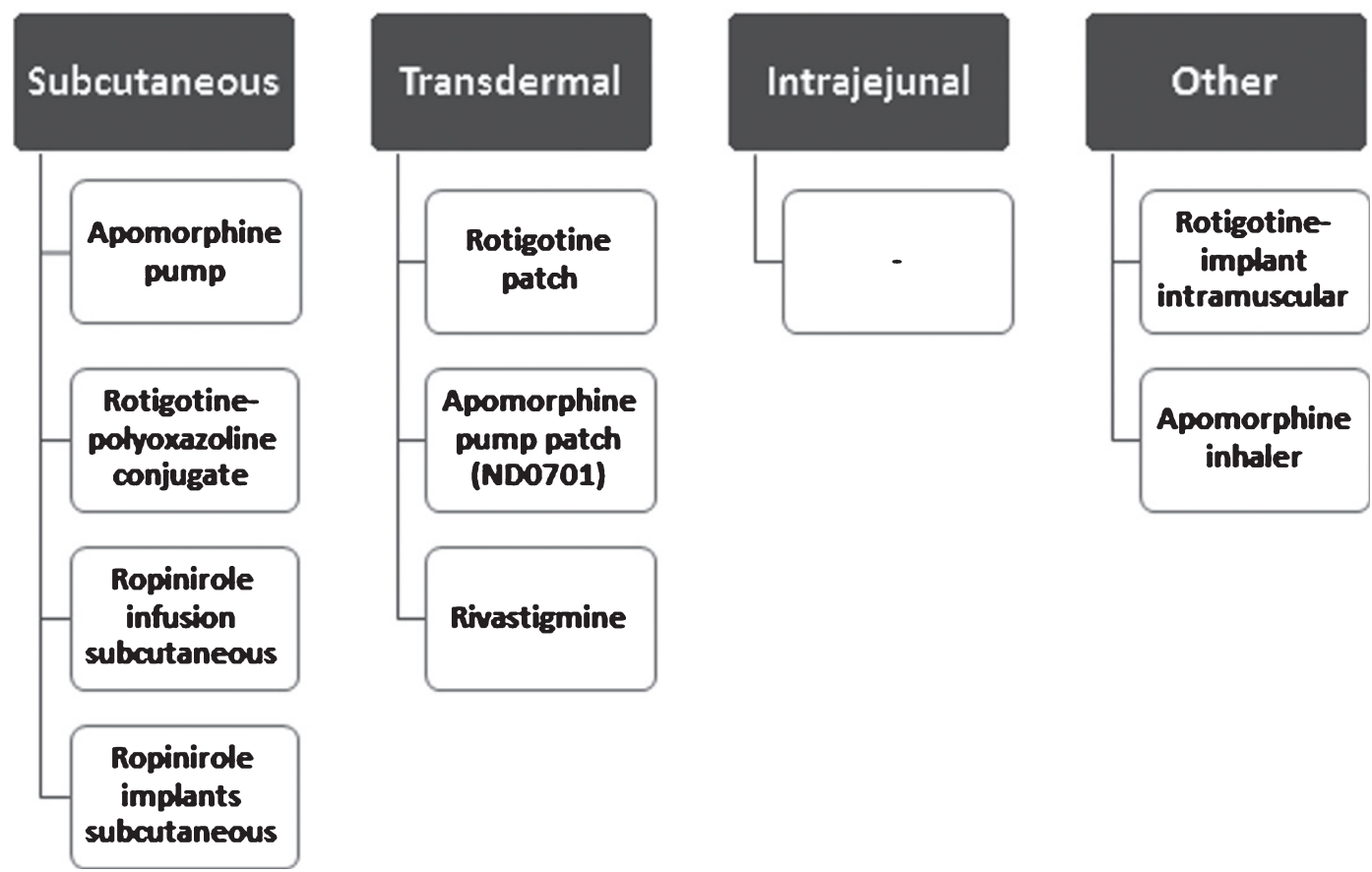

Fig. 1. Overview of continuous dopaminergic therapy in Parkinson's disease.

(around 7\%), device-related infections (around 6\%), and device dislocations (around $5 \%$ ) [17, 24].

Future development of IJLI and other Levodopa based therapies

Recently, a new formula for IJLI has been developed where Levodopa/Carbidopa gel was combined with Entacapone to extend the half-life of levodopa [25]. In a small randomized cross-over trial, it was shown that when levodopa content in the gel was lowered by $20 \%$ and Entacapone added, this was as effective as the normal IJLI gel without Entacapone. This in effect showed that Entacapone allows for a $20 \%$ reduction of the Levodopa dose in IJLI therapy [25]. The reduction of solution volume needed may prevent high L-Dopa doses, that increase the treatment cost and the risk for side-effects, such as hyperkinesia, hallucinations, hyperhomocysteinemia, B12-deficiency and polyneuropathy [26] and create the possibility to introduce smaller pump devices. A recent approach has been to combine the 
third generation COMT inhibitor opicapone, effective once a day with IJLI infusion which may reduce the IJLI dosing by 20-30\% (Taddei et al., unpublished data).

A novel levodopa/carbidopa solution allowing continuous intravenous and subcutaneous (sc) infusion is currently being tested in a Phase I, multicenter trial in Sweden (IPO-001, NCT03419806). Another example is the Levodopa pump patch, ND0612, whereby a pump is attached to a transdermal patch [27-29]. This formulation consists of Levodopa and Carbidopa and is being developed for patients with moderate to severe motor disease. The subcutaneous route administration of ND0612 shows sustained levodopa plasma levels, thus offering a new approach to continuous drug delivery. Currently, the available data is showing that continuous subcutaneous ND0612 delivery yielded steady-state plasma concentrations estimated to be in a therapeutic window and a Phase 2 trial showed reduced Off-time of over two hours compared with placebo. Further analysis showed good tolerability and transient local skin reactions were the main adverse events [27-29].

Other subcutaneous L-dopa alternatives are also currently under development, such as ABBV-951 (NCT03374917). Subcutaneous administration of continuous therapy is a relatively convenient way of treatment and the main problems related to it are local skin reactions and the amount of L-dopa that can be given subcutaneously daily. Another intuitive example of trying to achieve a more continuous LD delivery in a non-invasive way is DopaFuse that has undergone a Phase II study. It is a little device that is worn in the back of the mouth and slowly delivers the drug. INP103 on the other hand (NCT03541356) is trying to utilize levodopa during OFF- episodes by the intranasal route and is currently recruiting for a phase IIa study in Australia.

\section{CURRENTLY AVAILABLE NON-LEVODOPA BASED STRATEGIES}

\section{Rotigotine transdermal patch}

The transdermal RTG patch has been in clinical use for the best part of 15 years now and was the first transdermal therapy widely available to PD patients in all stages of the disease. RTG shows steady and stable plasma levels throughout the day, including night time [30]. Interestingly, as Apomorphine, RTG is one of the few dopamine agonists with a significant effect on D1-type receptors, unlike, e.g., pramipexole which has potent D3 activity. RTG not only has a clear effect on motor symptoms in PD [31, 32], but its efficacy has also been shown for several NMS, concerning positive effects mainly on sleep and (dopamine-fluctuation related) pain [33-35].

\section{Future development of Rotigotine}

Studies addressing the possibility of improving the delivery of Rotigotine are currently underway. One way of improving delivery is to combine drugs with polyoxazolines, biodegradable bioconjugate polymers, with potential of greater control of drug delivery and release rate. Such a RTGpolyoxazoline conjugate, delivered subcutaneously, has entered into a phase 1 study in de novo PD patients (NCT02579473). In a PD rat model, this drug (SER214) showed a prolonged RTG half-life with reduced motor complications [36].

An extended-release microsphere formulation of Rotigotine, LY 03003, is being developed as an intramuscular injection and is intended for once weekly administration. If proven to be bioequivalent to transdermal RTG patch, it could provide a useful alternative that simplifies treatment administration and compliance (NCT03589066). According to the manufacturer there are also plans on developing the formulation for monthly injections. Small polymeric, Rotigotine-loaded implants that were inserted subcutaneously in rats have shown a sustained drug release for about 40 days, indicating that further development of such drug formulations may provide a convenient alternative for continuous dopaminergic stimulation in PD patients [37].

\section{Ropinirole}

Ropinirole is a D2/D3 dopamine agonist that is used in PD patients in all stages of disease as immediate and extended release tablets. A study on Ropinirole delivered by subcutaneous implants that can hopefully deliver the medication under a 3-month period is under way (NCT03250117), while continuous subcutaneous infusion with ropinirole has been previously tested in animals [38].

\section{Apomorphine}

The use of Apomorphine subcutaneous injections for the treatment of motor symptoms in advanced PD has been documented as far back as 1951 [39]. The evidence for the clinical use of Apomorphine 
in addressing motor symptoms and motor fluctuations in PD was, until very recently, based on the results from a number of open-label trials [40]. In 2017, a large randomized, placebo-controlled study (TOLEDO study) showed the superiority of Apomorphine compared to placebo with a significant and clinically meaningful reduction in Off- time of approximately two hours and an equal extension of On-time without troublesome dyskinesia [41]. However, a significant benefit on quality of life was not observed. Apomorphine infusion therapy also appears to have a focal effect on NMS [19] with the main effects on mood/apathy, perceptual problems and memory. The indications for Apomorphine therapy are the same as for IJLI, although care should be taken with patients who experience drug-related hallucinations or impulse control disorders. Such patients need not necessarily be excluded as visual hallucinations can often be handled through dose adjustments [21].

\section{Future development of Apomorphine}

Studies are currently underway to assess the effect of Apomorphine delivery via a pump patch rather than via classical infusion [42].

The apomorphine-based product ND0701 is delivered via a patch attached to a pump. Results obtained so far have shown that the bioavailability of apomorphine from ND0701 was comparable to that of commercial Apomorphine and that the systemic and local safety profile of ND0701 was non-inferior to commercial Apomorphine with, e.g., less prominent nodules formation [43]. This idea is identical to the one described for the levodopa-based therapies and ND0701 is aimed at patients who may not respond to the levodopa patch-pump technology (see above).

\section{Rivastigmine}

Rivastigmine was first approved in Switzerland in 1997 and later in the USA in 2000 for the symptomatic treatment of mild-to-moderate Alzheimer's disease. Following this, it was approved in many countries worldwide in 2006 for the symptomatic treatment of mild-to-moderate PD dementia [44] in advanced PD. The patches provide a smooth and continuous transcutaneous drug delivery, unlike oral capsules. The Rivastigmine $9.5 \mathrm{mg} / 24 \mathrm{~h}$ patch provides comparable exposure to the highest capsule dose $(12 \mathrm{mg} /$ day $)$, but with prolonged efficacy time and lower peaks [44]. The usefulness of
Rivastigmine extends beyond improving cognition. A small pilot trial has shown an improvement in REM sleep behavior episodes assessed by means of bed partner diaries [45]. Another small study has shown that Rivastigmine may improve certain elements of postural control and reduce falls [46, 47], although this requires further studies as the positive findings are not paralleled by marked effects in clinical practice.

\section{Amantadine}

Although Amantadine is an oral therapy, and as such not within the scope of this review, we have referenced it as the single-dose tablet can be considered a continuous therapy and furthermore aids in delivering simplified treatment regimes in PD patients. Amantadine has still its role in PD treatment and is mainly used as an antidyskinetic and a novel extended release formulation ADS-5102, that is used 1 time daily, has recently undergone a Phase III trial in France with promising results in reducing levodopa-induced dyskinesias and even mildly reducing OFF-time [48].

\section{SUMMARY AND SPECULATION ABOUT FUTURE DEVELOPMENTS}

Although the current continuous therapies are not disease-modifying, they clearly provide robust symptomatic relief of both motor and non-motor symptoms related to the disease in advanced PD. The developments currently underway appear to be attractive concepts, but there is still much left to improve with regards to efficacy and safety of these treatments. Even so, the drive for more efficacious and less invasive and costly alternatives to the current treatments is likely to benefit patients with advanced PD in the future.

Further developments of the Levodopa-based therapies, such as IJLI, are likely to focus primarily on achieving highly concentrated infusion solutions in order to reduce pump size and weight. Addressing night-time delivery improving sleep and nocturnal motor symptoms is also important. First steps towards such treatments are the addition of COMT inhibitors to IJLI therapy and the $24 \mathrm{~h}$ transcutaneous Rotigotine patch, while IJLI is also in many cases given on a 24-hour basis. Finally, efforts should be made to use existing continuous therapies, such as Rivastigmine, for other indications. Exploratory results have shown that this drug may in fact not only address cognitive problems in PD, but also gait, underlining the concept 
of the cholinergic subtype of PD associated with gait disorders $[49,50]$.

Although not classified as CDD, cell-based therapies and gene therapy methodology are also under development, with an aim to achieve a more continuous and physiological dopaminergic stimulation in the areas of the brain that these techniques are applied to. These methods are still purely experimental, but that not least the use of stem cell-based techniques might accelerate this development. The variability and symptom fluctuations of PD can be better captured by digital technology such as wearables and sensors and may become regular in clinical practice in future. Monitoring devices, whether it be devoted devices worn by the patients, i.e., a wearable accelerometer, software/applications on patients' mobile devices measuring movement patterns or even devices measuring levodopa levels similar to those used for glucose monitoring in diabetes, could provide a monitoring aid in treating patients with continuous dopaminergic stimulation. A further step could also be an interaction the monitoring with the treatment providing devices, creating a biofeedback loop, thus minimizing motor fluctuations consistently, with minimal patient/doctor intervention, taking us a step further in personalized patient care.

The ultimate aim should be a continuous therapy that is capable of release throughout the 24 hours of a day and that holistically addresses motor and nonmotor symptoms, preferably through a personalized medicine for PD approach where patients' individual symptoms are taken into account [50].

\section{ACKNOWLEDGMENTS}

DW and SG are to be considered as joint first authors. DW reports a Fellowship grant from Britannia Pharmaceuticals. GS reports no potential conflict of interest. KRC reports consultancy fees from Britannia Pharmaceuticals, UCB, AbbVie, Otsuka, Mundipharma, Zambon, Profile, Bial, Sunovion, Merz, Pfizer, and Roche, outside the submitted work. $\mathrm{KRC}$ has also been an advisor to UCB, Bial, AbbVie, Merz, Sunovion, Zambon, Britannia Pharmaceuticals, Airliquid, and Jazz Pharma, and Pfizer, outside the submitted work. He has also received grants from the EU, EU Horizon 2020, Parkinson's UK, Medical Research Council (MRC) UK, MRC Singapore, National Parkinson Foundation, Kirby Laing Foundation, National Institute of Health Research (NIHR), and NIHR Biomedical Research Centres, outside the submitted work. PO reports consultancy and speaker related activities fees from AbbVie, Britannia, Boehringer-Ingelheim, Nordic Infucare, UCB, and Zambon and royalties from Uni-Med Verlag.

\section{REFERENCES}

[1] Olanow CW, Obeso JA, Stocchi F (2006) Continuous dopamine-receptor treatment of Parkinson's disease: Scientific rationale and clinical implications. Lancet Neurol 5, 677-687.

[2] Bibbiani F, Costantini LC, Patel R, Chase TN (2005) Continuous dopaminergic stimulation reduces risk of motor complications in parkinsonian primates. Exp Neurol 192, 73-78.

[3] Rascol O, Brooks DJ, Korczyn AD, De Deyn PP, Clarke CE, Lang AE (2000) A five year study of the incidence of dyskinesia in patients with early Parkinson's disease who were treated with ropinirole or levodopa. $N$ Engl J Med 342, 1484-1491.

[4] Nutt JG, Obeso JA, Stocchi F (2000) Continuous dopamine receptor stimulation in advanced Parkinson's disease. Trends Neurosci 23, 109-115.

[5] Titova N, Schapira AHV, Chaudhuri KR, Katunina E, Jenner P (2017) Nonmotor symptoms in experimental models of Parkinson's disease. Int Rev Neurobiol 133, 63-89.

[6] Grosset KA, Grosset DG (2007) Effect of educational intervention on medication timing in Parkinson's disease: A randomized controlled trial. BMC Neurol 16, 7-20.

[7] Malek N, Grosset DG (2015) Medication adherence in patients with Parkinson's disease. CNS Drugs 29, 47-53.

[8] Grosset D, Antonini A, Canesi M, Pezzoli G, Lees A, Shaw K, Cubo E, Martinez-Martin P, Rascol O, Negre-Pages L, Senard A, Schwarz J, Strecker K, Reichmann H, Storch A, Löhle M, Stocchi F, Grosset K (2009) Adherence to antiparkinson medication in a multicenter European study. Mov Disord 24, 826-832.

[9] Straka I, Minár M, Gažová A, Valkovič P, Kyselovič J (2018) Clinical aspects of adherence to pharmacotherapy in Parkinson disease: A PRISMA-compliant systematic review. Medicine (Baltimore) 97, e10962.

[10] Chaudhuri KR, Qamar MA, Rajah T, Loehrer P, Sauerbier A, Odin P, Jenner P (2016) Non-oral dopaminergic therapies for Parkinson's disease: Current treatments and the future. NPJ Parkinsons Dis 2, 16023.

[11] Titova N, Qamar MA, Chaudhuri KR (2017) The nonmotor features of Parkinson's disease. Int Rev Neurobiol 132, 33-54.

[12] Verhagen Metman L, Stover N, Chen C, Cowles V, Sweeney M (2015) Gastroretentive carbidopa/levodopa, DM-1992, for the treatment of advanced Parkinson's disease. Mov Disord 30, 1222-1228.

[13] Nyholm, D (2007) The rationale for continuous dopaminergic stimulation in advanced Parkinson's disease. Parkinsonism Relat Disord 13, S13-S17.

[14] Olanow CW, Kieburtz K, Odin P, Espay AJ, Standaert DG, Fernandez HH, Vanagunas A, Othman AA, Widnell KL, Robieson WZ, Pritchett Y, Chatamra K, Benesh J, Lenz RA, Antonini A, LCIG Horizon Study Group (2014) Double-blind, double-dummy, randomized study of continuous intrajejunal infusion of levodopa-carbidopa intestinal 
gel in advanced Parkinson's disease. Lancet Neurol 13, 141-149.

[15] Juhász A, Aschermann Z, Ács P, Janszky J, Kovács M, Makkos A, Harmat M, Tényi D, Karádi K, Komoly S, Takáts A, Tóth A, Nagy H, Klivényi P, Dibó G, Dézsi L, Zádori D, Annus Á, Vécsei L, Varannai L, Kovács N (2017) Levodopa/carbidopa intestinal gel can improve both motor and non-motor experiences of daily living in Parkinson's disease: An open-label study. Parkinsonism Relat Disord 37, 79-86.

[16] Antonini A, Nitu B (2018) Apomorphine and levodopa infusion for motor fluctuations and dyskinesia in advanced Parkinson disease. J Neural Transm 125, 1131-1135.

[17] Antonini A, Poewe W, Chaudhuri KR, Jech R, Pickut B, Pirtošek Z, Szasz J, Valldeoriola F, Winkler C, Bergmann L, Yegin A, Onuk K, Barch D, Odin P, GLORIA study coinvestigators (2017) Levodopa-carbidopa intestinal gel in advanced Parkinson's: Final results of the GLORIA registry. Parkinsonism Relat Disord 45, 13-20.

[18] Ciurleo R, Corallo F, Bonanno L, Lo Buono V, Di Lorenzo G, Versaci R, Allone C, Palmeri R, Bramanti P, Marino S (2018) Assessment of Duodopa ${ }^{\circledR}$ effects on quality of life of patients with advanced Parkinson's disease and their caregivers. J Neurol 265, 2005-2014.

[19] Martinez-Martin P, Reddy P, Katzenschlager R, Antonini A, Todorova A, Odin P, Henriksen T, Martin A, Calandrella D, Rizos A, Bryndum N, Glad A, Dafsari HS, Timmermann L, Ebersbach G, Kramberger MG, Samuel M, Wenzel K, Tomantschger V, Storch A, Reichmann H, Pirtosek Z, Trost M, Svenningsson P, Palhagen S, Volkmann J, Chaudhuri KR (2015) EuroInf: A multicenter comparative observational study of apomorphine and levodopa infusion in Parkinson's disease. Mov Disord 30, 510-516.

[20] Lowin J, Sail K, Baj R, Jalundhwala YJ, Marshall TS, Konwea H, Chaudhuri KR (2017) The cost effectiveness of levodopa/carbidopa intestinal gel compared to standard care in advanced Parkinson's disease. J Med Econ 20, 1207-1215.

[21] Timpka J, Nitu B, Datieva V, Odin P, Antonini A (2017) Device-aided treatment strategies in advanced Parkinson's disease. Int Rev Neurobiol 132, 453-474.

[22] Merola A, Romagnolo A, Zibetti M, Bernardini A, Cocito D, Lopiano L (2016) Peripheral neuropathy associated with levodopa-carbidopa intestinal infusion: A long-term prospective assessment. Eur J Neurol 23, 501-509.

[23] Loens S, Chorbadzhieva E, Kleimann A, Dressler D, Schrader C (2017) Effects of levodopa/carbidopa intestinal gel versus oral levodopa/carbidopa on B vitamin levels and neuropathy. Brain Behav 7, e00698.

[24] Titova N, Chaudhuri KR (2017) Intrajejunal levodopa infusion therapy for Parkinson's disease: Practical and pragmatic tips for successful maintenance of therapy. Exp Rev Neurother 17, 529-537.

[25] Senek M, Nielsen EI, Nyholm D (2017) Levodopaentacapone-carbidopa intestinal gel in Parkinson's disease: A randomized crossover study. Mov Disord 32, 283-286.

[26] Müller T, van Laar T, Antonini A, Odin P, Klostermann F, Grandas FJ, Ebersbach G, Urban PP, Valldeoriola F, Antonini A (2013) Peripheral neuropathy in Parkinson's disease: Levodopa exposure and implications for duodenal delivery. Parkinsonism Relat Disorders 19, 501-507.

[27] Giladi N, Caraco Y, Gurevich T, Djaldetti R, Olanow CW (2015) Stable levodopa plasma levels with ND0612 (levodopa/carbidopa for subcutaneous infusion) in Parkinson's disease (PD) patients with motor fluctuations [abstract]. Mov Disord 30, 1995.

[28] Giladi N, Caraco Y, Gurevich T, Djaldetti R (2015) Pharmacokinetics and safety of ND0612L (levodopa/carbidopa for subcutaneous infusion): Results from a phase II study in moderate to severe Parkinson's disease [abstract]. Neurology 84(Suppl. P1), 187.

[29] Giladi N, Caraco Y, Gurevich T (2015) Pharmacokinetic profile of ND0612L (levodopa/carbidopa for subcutaneous infusion) in patients with moderate to severe Parkinson's disease [abstract]. Mov Disord 30(Suppl. 1), S226.

[30] Elshoff JP, Braun M, Andreas JO, Middle M, Cawello W (2012) Steady-state plasma concentration profile of transdermal rotigotine: An integrated analysis of three, open-label, randomized, phase I multiple dose studies. Clin Ther 34, 966-978.

[31] Poewe WH, Rascol O, Quinn N, Tolosa E, Oertel WH, Martignoni E, Rupp M, Boroojerdi B, SP 515 Investigators (2007) Efficacy of pramipexole and transdermal rotigotine in advanced Parkinson's disease: A double-blind, double-dummy, randomised controlled trial. Lancet Neurol 6, 513-520.

[32] LeWitt PA, Lyons KE, Pahwa R (2007) Advanced Parkinson disease treated with rotigotine transdermal system: PREFER Study. Neurology 68, 1262-1267.

[33] Trenkwalder C, Kies B, Rudzinska M, Fine J, Nikl J, Honczarenko K, Dioszeghy P, Hill D, Anderson T, Myllyla V, Kassubek J, Steiger M, Zucconi M, Tolosa E, Poewe W, Surmann E, Whitesides J, Boroojerdi B, Chaudhuri KR (2011) Recover Study Group. Rotigotine effects on early morning motor function and sleep in Parkinson's disease: A doubleblind, randomized, placebo-controlled study (RECOVER). Mov Disord 26, 90-99.

[34] Chaudhuri KR, Martinez-Martin P, Antonini A, Brown RG, Friedman JH, Onofrj M, Surmann E, Ghys L, Trenkwalder C (2013) Rotigotine and specific non-motor symptoms of Parkinson's disease: Post hoc analysis of RECOVER. Parkinsonism Relat Disord 19, 660-665.

[35] Rascol O, Zesiewicz T, Chaudhuri KR, Asgharnejad M, Surmann E, Dohin E, Nilius S, Bauer L (2015) A randomized controlled exploratory pilot study to evaluate the effect of rotigotine transdermal patch on Parkinson's disease-associated chronic pain. J Clin Pharmacol 56, 852-861.

[36] Eskow Jaunarajs KL, Standaert DG, Viegas TX, Bentley MD, Fang Z, Dizman B, Yoon K, Weimer R, Ravenscroft P, Johnston TH, Hill MP, Brotchie JM, Moreadith RW (2013) Rotigotine polyoxazoline conjugate SER-14 provides robust and sustained antiparkinsonin benefit. Mov Disord 28, 1675-1682.

[37] Wang A, Liu Y, Liang R, Zhang X, Sun K, Wu Z, Liu W (2016) Preparation and evaluation of rotigotine-loaded implant for the treatment of Parkinson's disease and its evolution study. Saudi Pharm J 24, 363-370.

[38] Stockwell K, Virley D, Perren M, Iravani MM, Jackson MJ, Rose S, Jenner P (2008) Continuous delivery of ropinirole reverses motor deficits without dyskinesia induction in MPTP-treated common marmosets. Exp Neurol 211, 172179.

[39] Schwab RS, Amador LV, Lettvin JY (1951) Apomorphine in Parkinson's disease. Trans Am Neurol Assoc 56, 251-253.

[40] Garcia Ruiz PJ, Sesar Ignacio A, Ares Pensado B, Castro García A, Alonso Frech F, Alvarez López M, Arbelo González J, Baiges Octavio J, Burguera Hernández JA, Calopa Garriga M, Campos Blanco D, Castaño García B, 
Carballo Cordero M, Chacón Peña J, Espino Ibáñez A, Gorospe Onisalde A, Giménez-Roldán S, Granés Ibáñez P, Hernández Vara J, Ibáñez Alonso R, Jiménez Jiménez FJ, Krupinski J, Kulisevsky Bojarsky J, Legarda Ramírez I, Lezcano García E, Martínez-Castrillo JC, Mateo González D, Miquel Rodríguez F, Mir P, Muñoz Fargas E, Obeso Inchausti J, Olivares Romero J, Olivé Plana J, Otermin Vallejo P, Pascual Sedano B, Pérez de Colosía Rama V, Pérez López-Fraile I, Planas Comes A, Puente Periz V, Rodríguez Oroz MC, Sevillano García D, Solís Pérez P, Suárez Muñoz J, Vaamonde Gamo J, Valero Merino C, Valldeoriola Serra F, Velázquez Pérez JM, Yáñez Baña R, Zamarbide Capdepon I (2008) Efficacy of long-term continuous subcutaneous apomorphine infusion in advanced Parkinson's disease with motor fluctuations: A multicenter study. Mov Disord 23, 1130-1136.

[41] Katzenschlager R, Poewe W, Rascol O, Trenkwalder C, Deuschl G, Chaudhuri KR, Henriksen T, van Laar T, Spivey K, Vel S, Staines H, Lees A (2018) Apomorphine subcutaneous infusion in patients with Parkinson's disease with persistent motor fluctuations (TOLEDO): A multicentre, double-blind, randomised, placebo-controlled trial. Lancet Neurol 17, 749-759.

[42] Titova N, Chaudhuri KR (2016) Apomorphine therapy in Parkinson's and future directions (2016). Park Rel Disorder 33, S56-S60.

[43] Adar L, Durlach C, Yacoby Zeevi O, Fishelovitch D, Oren S (2017) ND0701: A new concentrated formulation of Apomorphine for continuous subcutaneous administration human PK data [abstract]. Mov Disord 32(suppl 2), Abstract $\# 1320$.
[44] Emre M, Aarsland D, Albanese A, Byrne EJ, Deuschl G, De Deyn PP, Durif F, Kulisevsky J, van Laar T, Lees A, Poewe W, Robillard A, Rosa MM, Wolters E, Quarg P, Tekin S, Lane R (2004) Rivastigmine for dementia associated with Parkinson's disease. N Engl J Med 351, 2509-2518.

[45] Di Giacopo R, Fasano A, Quaranta D, Della Marca G, Bove F, Bentivoglio AR (2012) Rivastigmine as alternative treatment for refractory REM behavior disorder in Parkinson's disease. Mov Disord 27, 559-561.

[46] McDonald J, Pourcher E, Nadeau A, Corbeil P (2018) A randomized trial of oral and transdermal rivastigmine for postural instability in Parkinson disease dementia. Clin Neuropharmacol 41, 87-93.

[47] Henderson EJ, Lord SR, Brodie MA, Gaunt DM, Lawrence AD, Close JC, Whone AL, Ben-Shlomo Y (2016) Rivastigmine for gait stability in patients with Parkinson's disease (ReSPonD): A randomised, double-blind, placebocontrolled, phase 2 trial. Lancet Neurol 15, 249-258.

[48] Pahwa R, Tanner CM, Hauser RA, Isaacson SH, Nausieda PA, Truong DD, Agarwal P, Hull KL, Lyons KE, Johnson R, Stempien MJ (2017) ADS-5102 (Amantadine) extended-release capsules for levodopa-induced dyskinesia in Parkinson disease (EASE LID Study): A randomized clinical trial. JAMA Neurology 74, 941-949.

[49] Mu J, Chaudhuri KR, Bielza C, de Pedro-Cuesta J, Larrañaga P, Martinez-Martin P (2017) Parkinson's disease subtypes identified from cluster analysis of motor and non-motor symptoms. Front Aging Neurosci 9, 301.

[50] Sauerbier A, Rosa-Grilo M, Qamar MA, Chaudhuri KR (2017) Nonmotor subtyping in Parkinson's disease. Int Rev Neurobiol 133, 447-478. 